\title{
Research on Undergraduates' Entrepreneurial Ecology System Based on Stage Characteristics of Undergraduates
}

\author{
Shu-Cheng ZHANG ${ }^{a,}$, , Hong-Bo LI ${ }^{b}$ \\ College of Management, Jiangsu University, Zhenjiang, China \\ a437114684@qq.com, 'blhb@ujs.edu.cn
}

\begin{abstract}
Keywords: Undergraduate entrepreneurship, Undergraduate entrepreneurial ecosystem, Entrepreneurial stage, Mechanism research.
\end{abstract}

\begin{abstract}
The entrepreneurial ecosystem of college students is a multi-agent construction and multi-factor driven system and its main function is to provide entrepreneurial support for college students' entrepreneurial subjects. The entrepreneurial subjects of college students have obvious stage characteristics in undertaking entrepreneurial activities. The differences in characteristics of the stage make the entrepreneurial subjects of college students have different needs for the elements of entrepreneurial ecosystem. This paper analyzes the stage characteristics of undergraduates' entrepreneurial subjects and studies the entrepreneurial ecosystem mechanism of college students that adapts to the stage characteristics of undergraduates.
\end{abstract}

\section{Research Background}

College students are the most creative group in society and have both a rich knowledge base and a spirit of pioneering and enterprising. Encouraging college students to participate in entrepreneurial activities is of great significance to promoting the economic development of our country. According to the "2016 China Undergraduate Employment Report" released by the My COS Research Institute, the self-employment rate of Chinese college students is only 3\%[1], which is much lower than the $20 \%-30 \%$ of the self-employment rate of developed country college students[2]. This shows that the vitality of our college students in participating in entrepreneurial activities has not been fully stimulated. As a multi-subject construction and multi-factor-driven system, college students entrepreneurial ecosystem as development support for college students' entrepreneurship plays an important role in promoting college students' entrepreneurship. The entrepreneurial subject of college students has obvious stage characteristics in the process of entrepreneurship. Therefore, according to the characteristics of the entrepreneurial stage of college students, the mechanism of college students' entrepreneurial ecosystem is studied, and it is of great practical significance to propose an ecological system mechanism that adapts to the entrepreneurial subject of college students.

\section{Literature Review and Summary}

Since the 1990s, the focus of the entrepreneurial research field has gradually shifted from research on the basic characteristics of entrepreneurs to research on the entrepreneurial process. In essence, entrepreneurship is the process of development over time, the evolution of subject characteristics, and the entrepreneurial process is dynamic and complicated. Therefore, it is necessary to clarify the stage characteristics that emerge during the entrepreneurial process, so as to accurately divide the stage and provide the premise and support for the mechanism research of the entrepreneurial ecosystem. Based on the important theoretical model Timmons model, Lu Xinwen divided the entrepreneurial process of college students into three stages in 2009: the entrepreneurial preparation stage, the establishment stage of the venture enterprise, the growth management stage of the new venture, and study the entrepreneurial process model of the college students based on the different characteristics of the entrepreneurial stage[3]. This article will refer to Lu Xinwen's division of the entrepreneurial stage and analyze and summarize the features of each stage.

With regard to the composition of entrepreneurial ecosystems, domestic and foreign researchers 
have conducted many research. Isenberg proposed a model including elements of policy, finance, culture, support, human capital, marketing and entrepreneurship in 2011[4]; Feld presented in 2012 a model of strong entrepreneurial leadership groups, intermediaries, network density, government, talent, support services, pillar companies that encourage and support entrepreneurship, investment capital, entrepreneurship exchange activities;

domestic scholars Yang Yong and others in 2014 built a factor structure model including incumbent companies, universities and research institutions, governments, financial institutions, intermediary agencies, and technology startups[6];Wang Zhong and others proposed a model centered on social enterprises in 2015 that includes elements such as the macro environment, government departments, media, mediation, scientific research institutions, and non-profit organizations[7].The entrepreneurial ecosystem of college students is a subsystem of the entrepreneurial ecosystem, and has the same and different features as the general entrepreneurial ecosystem. The model of the entrepreneurial ecosystem of college students based on the GEM entrepreneurial ecosystem proposed by Zhang Xiuche and others in 2017 is more representative that including college students, government, universities, society, companies, and families, which is of practical significance to construct an ecosystem mechanism that matches the stage characteristics of college students' entrepreneurship. Therefore, this article is based on this model for research

\section{An Analysis of College Students' Entrepreneurial Ecosystem Mechanism}

\section{The System Mechanism during the Entrepreneurial Preparation Stage}

In the entrepreneurial preparation stage, college students need to assess their own conditions and external conditions, and then make entrepreneurial choices, that is, decided to start a business. At this stage, the status of undergraduate entrepreneurship is a preliminary psychological intent to form a business, efforts to find suitable business opportunities for the venture, lack of strong resource integration capabilities and team management capabilities in terms of capabilities. At the same time, the resources of the entrepreneurial entity are still relatively lacking, and the entrepreneurial team has not been shaped. At this stage, the most urgent problem to be solved is the identification and utilization of business opportunities, efforts to form a strong entrepreneurial willingness, and further enhancement of all aspects of the capabilities needed for entrepreneurship.

According to the entrepreneurial ecosystem model of college students, the role of relevant factors in this stage is analyzed. The main role of the government: through the introduction of practical policies to support entrepreneurship for college students, such as broadening financing channels, providing entrepreneurial sites, allowing suspension of business, and providing quality supporting services, etc., that will generate a strong entrepreneurial attraction for college students and help them form their entrepreneurial aspirations. The main roles of universities are as follows: First, provide quality entrepreneurship education, through the establishment of specialized entrepreneurship education courses to help students master the knowledge of accounting, marketing, team management, etc., help students improve their ability to identify opportunities, and realize their own ability assessment. The second is to provide scientific and technological achievements that can be transformed. Colleges and universities, as high places of talents and gathering places for technological achievements, have abundant technological achievements. These technological achievements are important business opportunities for entrepreneurial entrepreneurs of college students to achieve entrepreneurship. The transformation of scientific and technological achievements through the entrepreneurial subject of college students can not only provide a considerable part of business opportunities for college students, but also help transform the technology. The main role of society is to provide a strong entrepreneurial culture and stimulate the entrepreneurial enthusiasm of college students. For example, the Yangtze River Delta and Pearl River Delta regions in China have a strong entrepreneurial atmosphere, which has boosted the entrepreneurial atmosphere of regional colleges and universities. The second is to provide abundant social funds, but it is less effective at this stage. The main role of the family: First, the impact of the concept of family employment, the family is the spiritual pillar of college students entrepreneurs, 
family support is crucial for the entrepreneurial choice of college students, Because Chinese university students have a strong ethical outlook, families have a great influence on their entrepreneurial choices. The second is to provide financial support for the initial stage of the venture. The college students with better family economic conditions have the ability to prevent and resolve the risk of venture capital investment. The family provides a strong financial support for the entrepreneurs of college students.

Therefore, in the entrepreneurial preparation stage, the elements of the entrepreneurial ecosystem of college students play an important role include: the government's support policy incentives, college entrepreneurship education and technological achievements, family spiritual and economic support. The influence of the entrepreneurial atmosphere in the society and the influence of the company's fostering support is less.

\section{The System Mechanism of the Establishment Stage of Start-up Companies}

At the establishment stage of the venture enterprises, college students have completed the psychological preparation and identification of business opportunities, and have relatively determined entrepreneurial goals. The main task at this stage is the development of business opportunities, which requires the ability to acquire and integrate resources, including the ability to acquire human resources, information resources, and financial resources. The role played by the elements in the entrepreneurial ecosystem of college students is also different at this time

According to the entrepreneurial ecosystem model of college students, this paper analyzes the role of various elements in the establishment stage of startup companies. The main role of the government: The government's entrepreneurial support policy for college students began to play a role at this stage. The government provided microloans to provide entrepreneurs with financial resources. Entrepreneurial open space for entrepreneurs provided infrastructure resources and provided high quality Supporting services, etc. These government resources have solved many problems for entrepreneurs of college students and helped them to grow rapidly. The main role of colleges and universities: Quality entrepreneurship education helps college entrepreneurs to enhance their abilities. At the same time, they help college entrepreneurs analyze the problems they face at each stage. Specific measures include: arranging professional entrepreneurial tutors, and helping entrepreneurs to further clarify entrepreneurial ideas through entrepreneurial competitions. The research and development of scientific and technological achievements in colleges and universities provide entrepreneurs with a follow-up, continuous technical support and protection. The main role of society: The role of society has begun to appear prominent at this stage, the main role is to provide a wealth of social funds. China's Yangtze River Delta, the Pearl River Delta region and other areas with a strong entrepreneurial atmosphere, there are a wealth of venture capital institutions, strategic investment institutions and other private capital organizations, these organizations provide a rich source of venture capital for college students in entrepreneurship. The main role of the company: The role of the company has also begun to highlight at this stage. New enterprises run by college students can provide more opportunities for existing enterprises, and promote cooperation between existing enterprises and new enterprises that provide a relatively broad market for entrepreneurs of college students. At the same time, existing companies have strong financial capabilities, can provide financial support for college entrepreneurs, and help college entrepreneurs get out of the initial financial difficulties. The main role of the family: The role of the family is still important at this stage. After making entrepreneurial decisions, family support is the driving force for college student entrepreneurs to continue their entrepreneurship. Like some college students with poor family economic conditions, their entrepreneurial ventures will bring financial risks to their families, and their entrepreneurial activities will encounter family opposition. At the same time, the family is still one of the sources of funds for the initial stage of entrepreneurship and good family economic conditions can help prevent the risk of venture capital investment.

Therefore, in the establishment stage of startup companies, the important roles played by the factors in the entrepreneurial ecosystem of college students include: the government's substantive 
support policies, support for more effective entrepreneurial education and technical achievements in universities, support for social funds, market support for enterprises, family support, these elements all play an important role.

\section{The System Mechanism of the Growth Management Phase of the New Venture}

In the stage of growth management of new start-ups, the development of business opportunities has entered a substantive stage. Funds have begun to enter in all aspects. Resources also have begun to enter, and the entrepreneurial team has also begun to grow. At this stage, the main problem faced by college student entrepreneurs include: how to attract more entrepreneurial talents to enter, form the advantages of the enterprise, stand firm on the market and allocate resources more efficiently? At this stage, the role of some of the internal elements of entrepreneurial ecosystem in college students began to weaken.

According to the entrepreneurial ecosystem model of college students, the role of the elements in the growth management stage of the newly-established enterprise is analyzed. The main role of the government: The role of the government's entrepreneurial support policy formulated by the government at this stage began to weaken, because the entry of funds in all aspects reduced the demand for financial support provided by government, and some infrastructure resources and supporting services could not meet the needs of enterprise development. This means that the government's incubation support starts to gradually withdraw. The main role of colleges and universities: The role of colleges and universities has also begun to weaken, but it is still irreplaceable. First of all, the undergraduates' knowledge of entrepreneurship at this stage is basically complete, and they do not need to rely entirely on classroom instruction in entrepreneurship education. However, colleges and universities still have replace ability in terms of technical support. Because start-up research and development capabilities are weak, facing the entry of market competitors, if they do not form effective market barriers, they will be defeated by strong market competitors. Technical support and protection are still important. The main role of society: At this stage, social capital still plays an important role. At the stage of the growth and management of start-up companies, the advantages of new start-up companies have not yet been fully established. Multiple rounds of financing are still very important for new start-ups of university students, and the disruption of social capital may lead to entrepreneurship failure. The main role of the company: The company continues to play an important role in this stage. Existing companies provide a relatively wide range of market for new start-up companies, and cooperation with existing companies can increase the visibility of new ventures and further expand the market for new start-up companies, while the existing company's financial support can also help the new start-up companies to continue to achieve development. The main role of the family: The supportive role of the family began to weaken, and family support still affected the entrepreneurial determination of college students. However, at this time the family economy no longer played an important role, even the current stage of entrepreneurial activities may not require family financial support.

Therefore, in the growth management stage of the new venture, the changes in the elements of the entrepreneurial ecosystem of university students include: Supportive policies of the government, entrepreneurship education in colleges and universities, and economic support for families have begun to weaken. However, the technical support of universities, the support of social funds, the market support of enterprises, and the spirit of the family still play an important role.

\section{Conclusions and Countermeasures}

Based on the analysis of the internal factors of the entrepreneurial ecosystem of college student in the above stages, we can draw the following conclusions: Firstly, the support of the entrepreneurial ecosystem elements needed by entrepreneurs of college students in different entrepreneurial stages is different, and each stage has different characteristics. Secondly, according to the different stages of college students' entrepreneurship, they should provide matching support for Student entrepreneurs. In the preparation stage of entrepreneurship, it is necessary to pay attention to the stimulating effect of government support policies, to conduct more scientific entrepreneurship 
education in colleges and universities, to provide college students with the transformation of technological achievements, and to seek the family's spiritual and economic support. At the establishment stage of start-up companies, the government's substantive support policies, the support of entrepreneurship education and technical achievements provided by universities, the support of social funds, the market support of enterprises, the spirit and economic support of family all play an important role. Therefore all aspects need to be valued. In the growth management stage of new start-up companies, the government's support policies, entrepreneurship education in colleges, and family's economic support have begun to weaken. Undergraduate entrepreneurs should pay more attention to the support of college's technical achievements, the support of social funds, the market support of enterprises, and the family Spiritual support. Therefore, as a college student entrepreneur, it is necessary to make good use of the resources of the entrepreneurial ecosystem. As a builder of the entrepreneurial ecosystem of college students, it is necessary to provide university students with supporting system resources.

\section{Acknowledgements}

This research was supported by the Jiangsu Provincial Social Science Fund and the Key Projects of Philosophy and Social Sciences of Universities in Jiangsu Province. The project is: Research on Evaluation System of Innovative Entrepreneurship Ecosystem in Colleges and Universities, 17GLB001; Research on Entrepreneurship Practice of University Students Based on Web Embedment, 2016ZDIXM037. I would like to express my gratitude to my master graduate student tutor Hong-Bo Li. His careful guidance has greatly helped my paper writing. He urged me to form my own research ideas at the end of the first year of postgraduate students. I would also like to thank my brothers and sisters for their help and provided many valuable comments during my writing of the dissertation.

\section{References}

[1] My COS Research Institute., 2016 China University Student Employment Report [M]. Social Sciences Documentation Press, 2014.(In Chinese)

[2] Zhang Wenqiang., A comparative study of College Students' entrepreneurship at home and abroad [J]. Henan Social Sciences, 2013, 21(8):72-74.(In Chinese)

[3] Lu Xinwen. Study on the Model of Chinese University Students Entrepreneurship Process Based on Timmons Model [J]. Heilongjiang Researches on Higher Education, 2009(5):13-16.(In Chinese)

[4] Isenberg, Daniel J. “The Entrepreneurship Ecosystem Strategy as a New Paradigm for Economic Policy.," Institute of International European Affairs(2011): n. pag. Institute of International European Affairs. Web

[5] Feld B. Startup communities: Building an Entrepreneurial Ecosystem in Your City[M]. 2015.

[6] YANG Yong, WANG Zhijie. Study on the Mechanism of Regional Entrepreneurial Ecosystems and Policy Simulation [J]. Science of Science and Management of S.\&.T,2014,35(12):99-108.(In Chinese)

[7] Wang Zhong. The Internal Mechanism and Case Study on the Formation of Social Entrepreneurship Ecosystem Dominated by Social Enterprise [A]. China Management Modernization Research Association., Fudan Management Scholarship Foundation. Proceedings of the 10th (2015) Annual Conference of Chinese Management [C]. China Management Modernization Research Association, Fudan Management Scholarship Foundation:,2015:11.(In Chinese) 
[8] Zhang Xiue, Zhang Baowen. A Study on the Construction of University Student Entrepreneurial Mechanism Based on GEM Entrepreneurial Ecosystem [J]. Economic Review, 2017(02):45-49.(In Chinese) 